\title{
SAME AS IT EVER WAS: THE SEARCH FOR EVIDENCE OF INCREASING HYPERCOMPETITION
}

\author{
GERRY MCNAMARA, ${ }^{*}$ PAUL M. VAALER ${ }^{2}$ and CYNTHIA DEVERS ${ }^{3}$
1 The Eli Broad School of Management, Michigan State University, East Lansing,
Michigan, U.S.A.
2 Fletcher School of Law and Diplomacy, Tufts University, Medford, Massachusetts,
U.S.A.
${ }^{3}$ College of Business Administration, Central Michigan University, Mount Pleasant,
Michigan, U.S.A.
}

Some strategy scholars and practitioners contend that markets have become increasingly hypercompetitive in recent years. We examine this contention by analyzing industry and business performance patterns in a broad sample of firms drawn from the Compustat Industry Segment database for the 1978-97 period. We find little support for the argument that markets have become more hypercompetitive. From the late 1970s to the late-1980s we observe decreased performance and market stability, consistent with increasing hypercompetition contentions. From the late 1980s to the mid-1990s, however, trends reverse and performance and market stability increase. For strategy research, our results suggest that hypercompetitive perspectives are important but no more so now than they were in recent years. For practice, our results suggest that managers today face markets no more dynamic and opportunities to gain and sustain competitive advantage no more challenging than in the past. Accordingly, they should continue developing a portfolio of skills to manage businesses whether conditions are increasingly stable or unstable. Copyright (c) 2002 John Wiley \& Sons, Ltd.

Have markets and businesses operating within them become more 'hypercompetitive' of late? This paper examines empirical support for arguments that business performance has, in recent years, become less dependent on stable market positions, resource configurations, corporate practices and industry structures, and more dependent on adroit management of fluid, short-term factors in increasingly volatile markets (e.g., MacMillan, 1989; D’Aveni, 1994, 1995; Thomas, 1996; Hamel, 2000).

These arguments contribute to what is, perhaps, the central debate in the strategic management field: how to explain differences in business performance (Rumelt, Schendel, and Teece, 1991). Classical industrial organization economics ('IO')

Key words: hypercompetition; performance stability; sustainable advantage

${ }^{*}$ Correspondence to: Gerry McNamara, Broad Graduate School of Management, Michigan State University, N475 North Business Complex, East Lansing, MI-48824-1122, U.S.A. stresses the importance of stable structural barriers limiting competitive entry and enriching incumbent firms (Bain, 1956; Porter, 1979). A contrasting corporate strategy perspective notes the importance of long-term competence in corporate oversight and control of resources utilized by affiliated businesses across different industries as an important determinant of performance (Chandler, 1962; Montgomery, 1979). A third perspective emphasizes neither industry structures nor corporate relationships but an intraindustry view highlighting the importance of fixed and idiosyncratic configurations of business-specific resources and hard-to-replicate positioning within an industry that result in sustainable differences in business returns (Porter, 1980; Wernerfelt, 1984; Barney, 1991).

A radically different, 'hypercompetitive' perspective (D'Aveni, 1994, 1995) contrasts with these other three strategic management perspectives, and has recently emerged in the strategy literature as 
a fashionable alternative. With hypercompetition, assumptions of market stability are replaced by notions of inherent instability and change (D’Aveni, 1994). Reliance by managers on stable industry structures, corporate forms and competencies, and business-specific resources is problematic in this world. Existing industry structures favoring incumbents may be upended by, say, technological innovations creating new opportunities for potential entrants (Schumpeter, 1950; Thomas, 1996). Corporate organizational approaches designed to fit one stable environment must be reoriented to respond to the need for greater flexibility to handle, potentially, continually shifting environments (Volberda, 1996). Corporate competencies are eroded by frequent discontinuities (Hamel, 2000). Idiosyncratic business-specific knowledge bases are rendered obsolete or even misleading by shifts in basic market relationships (Argote, 1999). Performance trends are, therefore, inherently more difficult to sustain in such markets. Persistently successful businesses, if any, emphasize entrepreneurship, adaptability to unstable and fast-changing market circumstances, and adroit management of fluid, often ephemeral assets and dynamic capabilities (Kirzner, 1973; Lei, Hitt, and Bettis, 1996; Teece, Pisano, and Shuen, 1997; Brown and Eisenhardt, 1998).

D'Aveni suggests that the antecedents of this transformational process in many markets are exogenous and endogenous factors that became more widespread in the 1980s and 1990s. An increased pace of innovation during this period both within individual businesses and among joint ventures and consortia shortened product cycles and undermined previously stable market positions based on superior technologies. The 1980s and 1990s also saw deregulation and liberalization of entry in industries previously exhibiting stable competitive patterns and operating returns for incumbents. Increased foreign direct investment and international trade agreements helped to globalize these local and national trends. Less aggressive enforcement of antitrust laws, greater emphasis on responsiveness to the short-term demands of capital markets, and a culture celebrating entrepreneurship, experimentation, and competition also contributed to the hypercompetitive shift in many industries during this time.

D'Aveni's view has not become a dominant view within strategic management, but many of its central tenets have gained popularity among strategy researchers and practitioners. For example, Thomas (1996: 221) finds evidence of a generalized 'hypercompetitive shift' across U.S. industries from the 1950s to the early 1990s, leading him to conclude that 'competition in the American economy has fundamentally changed over the last few decades from static to dynamic.' Hamel (2000) argues that basic organizational and market assumptions in strategy merit reassessment given recent increases in the speed of change in their environments, a view echoed by Brown and Eisenhardt (1998) when referring to high-velocity industries transformed by 'new economy' technologies. Assumptions about increasing instability of technology-based advantages are echoed by Bettis and Hitt (1995) in describing a 'new competitive landscape' emerging in the 1990s. Indeed, assumptions and prescriptive implications of an emerging 'strategic entrepreneurship' perspective in this decade (Hitt et al., 2001) exhibit several similarities to those maintained by D'Aveni and other hypercompetition proponents in the previous decade. For example, as with hypercompetition, a strategic entrepreneurship view assumes increased instability in the manager's environment and suggests the pursuit of more flexible organizational boundaries and strategies (Amit and Zott, 2001), as well as competitive advantage based on exploitation of short-term opportunities arising from greater environmental uncertainty (Shane and Venkataraman, 2000).

In this context, it is not surprising that academics and practitioners might simply take as given the increasing relevance of the hypercompetition perspective and the shift in markets and business strategy it implies. For example, Alavi, Yoo, and Vogel (1997: 1329), in a study of management education, maintain that 'institutions seek to adapt to changes in an increasingly complex and dynamic world.' Johnson and Greening (1999: 564) hold that 'strategic decision makers in the 1990s have seen the emergence of a hypercompetitive global marketplace.' ${ }^{1}$ In a more practitioneroriented vein, Schultz (1998: 20), describes for managers the 'hypercompetitive marketplace of the $21^{\text {st }}$ century,' while Harvey, Novicevic, and

\footnotetext{
${ }^{1}$ For additional studies that note a similar hypercompetitive shift, see Lau and Woodman (1995), Grant (1996), Hanssen-Bauer and Snow (1996), Illinitch, D'Aveni, and Lewin (1996), Nohria and Gulati (1996), Schein (1996), Volberda (1996), and Rindova and Kotha (2001).
} 
Kiessling (2001: 599) survey 'today's hypercompetitive landscape.' There is also evidence that this view has been accepted by some in related fields. For example, Sharma (2001: 125) analyzes consumer-salespeople interactions in 'this era of hypercompetition,' while Burke (1997: 18) discusses the impact of 'today's business environment of hypercompetition' on human resource practices.

As, perhaps, with any developing research perspective, minority views exist suggesting that hypercompetition within markets may ebb and flow in cycles (e.g., Gimeno and Woo, 1996; Bogner and Barr, 2000) or develop in specific market contexts only in the presence of certain contingent factors (e.g., Nault and Vandenbosch, 1996). But these exceptions highlight the dominant view outlined above that hypercompetition's destabilizing effects on a broad range of markets are thought to have generally increased in the 1980s and 1990s. If supported with empirical evidence from a similarly broad range of markets observed during this time, then the hypercompetition perspective might merit greater attention and importance among strategy researchers than is currently fashionable. If, on the other hand, broad evidentiary support from the 1980s and 1990s is missing, then the current popularity of this view might merit closer scrutiny as to how and why a substantial body of academic and practitioner work in this vein has recently found favor.

\section{HYPOTHESIS DEVELOPMENT}

\section{Fundamental research proposition}

The discussion above highlights the key distinctions between hypercompetitive perspectives and other strategy perspectives. Whether exogenously or endogenously driven, the frequency of strategic decision making under hypercompetition is greater compared to other strategy perspectives. The RBV perspective assumes that differences in business performance over time derive largely from differences in the fixed resources businesses have drawn from factor markets. Similarly, IO explains business performance differences based on fixed interindustry structural factors. In contrast, businesses in hypercompetitive markets must make frequent decisions to reestablish their role in changing markets. Decisions regarding resource selection, market positioning, and market entry and exit occur much more frequently in hypercompetitive markets. The increased frequency of decision making is evident in the discussion of the types of dynamic capabilities that Eisenhardt and Martin (2000) identify as key for building success in highvelocity environments. They identify four types of dynamic capabilities: integration capabilities such as product development processes and decision making; acquisition capabilities such as identifying and acquiring resources; reconfiguration capabilities such as transferring, replicating, and recombining resources; and capabilities to jettison resources. All of these require businesses to continually make resource and/or investment decisions.

If markets have changed substantially, necessitating increased strategic decision making by businesses, one of the key consequences of this hypercompetitive shift should be increased instability in patterns of business performance. While businesses may alter their decision processes to better fit the increasingly dynamic market, these businesses still have more opportunities to deviate from their current performance trend, both positively and negatively, compared to those in more stable environments. To illustrate this point, consider the following stylized example. We begin with a population of 100 businesses making strategic decisions regarding which fixed, long-term resources to acquire. In this case, the businesses begin in Year 0 with assorted resources and a range of performance attributes. But they are faced with a strategic decision likely to affect their performance over the next 5 years. They must decide which of multiple potential technological trajectories to pursue. Once taken, the decision is difficult to reverse in the next 5 years due to the necessary investments in capital expenditures and licensing agreements associated with the technologies. It turns out that 80 of the businesses in the population choose a technology that allows them to maintain their current level of performance. Ten of the businesses acquire technologies that allow them to improve their performance by 10 percent. The remaining 10 businesses pursue technologies that lead them to experience a 10 percent decline in performance.

At the end of Year 5, the businesses face a second investment choice. Again, 80 of the businesses choose technologies that allow them to maintain a stable pattern of performance. Ten choose investments that allow them to improve their performance by 10 percent, while 10 choose technologies that lead them to experience a 10 percent decline 
in performance. Thus at the end of Year 10, there have been two strategic decisions and the number of businesses experiencing stable performance over the entire 10 years after taking these decisions is $100 \times 0.8^{2}$ or 64 businesses.

Under hypercompetition, the frequency of strategic decision making increases substantially. In the context of our illustration, hypercompetition might imply that the length of the technology investments and/or rights agreements is much shorter, say, only 1 rather than 5 years long. If all of the other factors in this illustration remain the same, then, at the end of Year 10, there will have been 10 (not just two) strategic decisions and the number of businesses with stable performance over the entire 10-year period after taking these decisions is $100 \times 0.8^{10}$ or approximately 11 businesses. Thus, if businesses are equally well adapted to the hypercompetitive environment as they were to the stable environment, hypercompetition will result in more volatile performance patterns. To obtain the same number of businesses with stable performance under hypercompetition as obtained in the less frequent decision-making environment, the rate at which businesses pursue technologies that result in the same performance level as they currently experience would have to increase from 80 percent to nearly 96 percent.

This example illustrates the fundamental propositions for our empirical inquiry below. Hypercompetition increases the frequency of decision making and consequently decreases the stability of markets and business performance over time. Unless there is a rather substantial improvement in the decision-making capabilities of businesses, as markets become more hypercompetitive, there will be less stability in performance across the population over time.

Proposition 1: Increased hypercompetition has resulted in decreased business performance stability.

Proposition 2: Increased hypercompetition has resulted in decreased market stability.

These propositions lead to several testable hypotheses discussed below. The first hypothesis links increasing hypercompetition to decreases in the durability of abnormal business profitability. Previous research has demonstrated that abnormal returns tend to dissipate over time, regressing to

Copyright (c) 2002 John Wiley \& Sons, Ltd. mean levels, as a consequence of competitive pressures (Mueller, 1986; Jacobsen, 1988). D'Aveni (1995: 46-47), for example, cites several factors contributing to increased competitive pressures: lower barriers to entry; radical redefinition of market boundaries; frequent emergence of new technologies; shorter product life cycles; and aggressive action and reaction patterns by competitors. As a consequence, 'temporary advantage and short periods of profit are achievable until competitors catch up with or outmaneuver the aggressor's last competitive move' (D'Aveni, 1995: 46). A hypercompetitive shift in markets leads to greater competitive pressures that, in turn, should increase the rate of decay of abnormal business returns.

\section{Hypothesis 1: The durability of abnormal busi- ness returns has decreased.}

A second hypothesis links increasing hypercompetition to increasing rates of business mortality. Numerous researchers have argued that organizations exhibit inertial tendencies and find organizational change very difficult (e.g., March and Simon, 1958; Hannan and Freeman, 1977, 1984). Structural inertia theory (Hannan and Freeman, 1984) suggests that organizations tend to avoid change if possible and that fundamental transformations disrupt organizations and raise the risk of failure. Difficulty in organizational change is the consequence of both internal considerations, such as fixed investments, information constraints and asymmetries, political considerations, and organizational heritage, as well as external constraints, such as legal constraints, blind spots in external market knowledge, legitimacy considerations, and collective rationality problems (Hannan and Freeman, 1977). On a related note, fundamental changes in an organization's environment likely lessens the value of its key resources, such as technological assets (Tushman and Anderson, 1986) and institutional linkages (Baum and Oliver, 1991). Organizations that are not well adapted to their current environment and have seen the value of their resources depleted are more likely to be selected out (Tushman and Anderson, 1986; Henderson and Clark, 1990). Thus, unless organizations can fundamentally alter their capacity for change, increases in the rate of change in markets are likely to increase the rate at which businesses are selected out of the market. 
Hypothesis 2: Business mortality (exit from industries) has increased.

While we expect to see the effects of hypercompetition in patterns of performance by specific businesses, we would also expect to see consequences of the hypercompetitive shift at the broader industry level. Both the acts of competitors within industries and exogenous changes in the larger environment in which markets exist affect the characteristics of industries. While industry characteristics can be measured from many perspectives, two such characteristics likely to be affected by increasing hypercompetition are industry dynamism and munificence. Dynamism reflects the degree to which there is unpredictable change or volatility in an industry, while munificence reflects the degree to which an industry may support sustained growth (Sutcliffe, 1994; Castrogiovanni, 1991).

Industry dynamism should increase as hypercompetition unfolds. The lessening of the barriers to entry and exit allow for fundamental shifts in the structure of industries in very short periods of time (Porter, 1980). As, for example, substitute products and technologies converge and product life cycles shorten, stability in patterns of collective industry growth and performance should decline. We are more likely to see increasingly frequent and short-lived boom and bust cycles as industry after industry undergoes the hypercompetitive shift, and 'environments escalate toward higher and higher levels of uncertainty, dynamism, heterogeneity of the players, and hostility' (D'Aveni, 1995: 46).

\section{Hypothesis 3: Industry stability (dynamism) has decreased (increased).}

D'Aveni's argument about greater environmental 'hostility' in the presence of hypercompetition suggests our fourth and last hypothesis linking the hypercompetitive shift to reduced industry munificence. In making this link, he and others in this research stream (e.g., Thomas, 1996) build on IO arguments that structural changes in industries, such as declining entry barriers, and shortened product life cycles, reduce their overall capacity to support business growth. Such arguments contrast with other views in strategic management. For example, Tushman and Anderson (1986) suggest that the advent of radically new technologies may increase market opportunities by fostering the extension of a market's products and/or services to existing customers as well as to whole new classes of new customers. Given the disagreement on the effect of the hypercompetitive shift on industry munificence, we posit that, in line with D'Aveni's perspective, the level of market munificence will decline as the hypercompetitive shift has occurred.

$\begin{aligned} & \text { Hypothesis 4: Industry munificence has } \\ & \text { decreased. }\end{aligned}$

\section{METHODOLOGY}

\section{Data collection and sampling}

To find a representative sample of businesses and industries for testing these hypotheses about effects of increasing hypercompetition in the recent past, we follow other recent research examining the foundations of business performance (e.g., Roquebert, Phillips, and Westfall, 1996; McGahan and Porter, 1997) and draw on the Compustat Industry Segment database. ${ }^{2}$ We start with a total of 234,164 observations, which reflects financial data for all major lines of business in publicly traded U.S. corporations reporting in the 1978-97 period. ${ }^{3}$ We follow McGahan and Porter's (1997) suggestions for screening these data to arrive at our base sample for subsequent analyses. ${ }^{4}$ Once screened on these criteria, our

\footnotetext{
${ }^{2}$ For a discussion of the structure as well as the strengths and weaknesses of the Compustat Industry Segment database compared to other databases available for such study, see, for example, Roquebert et al. (1996).

${ }^{3}$ This 20 -year panel allows us to examine business segments that are reported using a consistent set of reporting guidelines over an extended period of time during which hypercompetition was purported to be increasing. Statement of Financial Accounting Standards 14 outlines the manner in which business segments would be identified for reporting to the SEC and was fully in force from 1978 to 1997 . We end our data period as of year-end 1997 since a change in accounting standards and related SEC disclosure regulations substantially altered the schema used to identify and report business-level financial data in later years.

${ }^{4}$ Following their recommendations, we eliminated observations if: (1) they did not contain a primary SIC designation; (2) they were from residual industry categories or government-related classifications; (3) they operated in financial services industries since their returns were difficult to compare with those in other industries; (4) they were from small businesses with sales and or assets less than \$10 million; (5) they had ROA values exceeding 100 percent since this suggests that the corporate parent either understated the assets of the business unit or consciously lumped profits into it for reporting purposes alone; or (6) they were described as 'corporate' or 'other' businesses since these did not appear to be active business units.
} 
base sample comprises a total of 114,191 businessunit ROA observations over the 1978-97 period. On average, the base sample has approximately 5700 business-unit observations for analysis in each year of the 20-year period of study. This average annual sample size is comparable to McGahan and Porter (1997).

Consistent with our research propositions and specific hypotheses, we use multiple dependent variables related to business performance. These measures include business-unit $\mathrm{ROA}^{5}$ and business-unit exit from an industry (mortality). We also utilize multiple dependent variables related to factors in the market (industry) environment where businesses compete. These measures include estimates of overall industry stability (dynamism) and munificence derived from business-unit sales, capital expenditures, and asset values.

\section{Variance components analysis}

As a preliminary analysis of our research propositions, we first examine the degree to which the ROA $r$ of a business unit operating in year $t$ in an SIC-delimited industry $i$ affiliated with corporation $k\left(r_{i k t}\right)$ is explained by mean returns for the business population $(\mu)$, economy-wide factors changing in impact from year to year (unstable) $\left(\gamma_{t}\right)$, industry-specific factors consistent across the period observed (stable) $\left(\alpha_{i}\right)$, unstable industry-specific factors $\left(\delta_{i t}\right)$, stable corporationspecific factors $\left(\beta_{k}\right)$, unstable corporation-specific factors $\left(\lambda_{k t}\right)$, stable business-specific factors $\left(\phi_{i k}\right)$ and unstable business-unit-specific factors $\left(\varepsilon_{i k t}\right)$. Following Rumelt (1991) and others, ${ }^{6}$ we estimate the impact of these independent variables ('IVs') terms on business-unit ROA by applying assumptions of a random effects model and treating each term as having a mean of zero and unknown but independent variance $\sigma_{\gamma}^{2}, \sigma_{\alpha}^{2}, \sigma_{\delta}^{2}, \sigma_{\beta}^{2}, \sigma_{\lambda}^{2}, \sigma_{\phi}^{2} \sigma_{\varepsilon}^{2}$. This permits us to partition the total variance in business-unit ROA for each 4-year window, $\sigma_{r}^{2}$, and assess the relative impact of each effect as a percentage of that total. For these analyses, we use

\footnotetext{
${ }^{5}$ McGahan and Porter (1997) vet the strengths and weaknesses of using ROA reported in the Compustat Industry Segment database as a performance measure.

${ }^{6}$ Studies by Rumelt (1991), Roquebert et al., (1996), Fox, Srinivasan, and Vaaler (1997), McGahan and Porter (1997), Brush, Bromiley, and Hendrickx (1999), Chang and Singh (2000), and others provide detailed discussions of variance components analysis.
}

the SAS VARCOMP procedure and the ANOVA method, also known as Henderson's Method II (SAS, 1989).

To perform these analyses, we add two methodological wrinkles. First, we divide the business units into 17 4-year moving windows (1978-81, 1979-82, 1980-83, .., 1994-97) and analyze the data in each 4-year window using a variance components (VC) model. We use 4-year moving windows to ensure that the insights we gain are not an artifact of business cycle or other factors linked to a particular starting and ending year in the 1978-97 period. $^{7}$ Second, we randomly subsample from each 4-year window and derive our $\mathrm{VC}$ estimates based on a weighted average of the subsamples analyzed. We use subsampling due to computational limitations associated with analyzing large samples using the VARCOMP procedure and ANOVA method. ${ }^{8}$

While we do not conduct formal hypothesis tests, these analyses do render important exploratory insights relevant to Proposition 1 about the business performance impact of increasing hypercompetition. Variance components related to unstable (stable) macroeconomic, industry, corporation, and business factors should increase (decrease) as we move from earlier to later 4-year windows.

\section{Autoregressive analysis}

To formally test Hypothesis 1, we use regression analysis to model ROA across all 20 years of our data according to a year-to-year autoregressive process similar to that used by Mueller (1986) and Jacobsen (1988). With this model, we can assess the degree to which abnormally higher or lower

\footnotetext{
${ }^{7}$ We recreated these analyses using variance in business-unit return on sales (ROS) as the performance metric and obtained results consistent with those reported above. We also found consistent results using variance in ROA with 3-, 5-, and 6year windows. All of these related analyses are available from the authors on request.

${ }^{8}$ Each 4-year window includes between 20,320 and 26,528 business-unit annual ROA sample observations. The data matrix used in the VARCOMP procedure with the ANOVA method can become exceedingly large. The technique creates a data column for every observed unit within each effect analyzed, including interaction effects. To permit variance components analyses of all sample observations, therefore, we randomly sorted the corporations for each 4-year window, partitioned the data within each 4-year window into 4000 observation subsamples (with the exception of the final subsample, which contained the remaining observations), and analyzed each of these subsets independently. We then calculated weighted average variance components estimates for all of the samples within each of the 4-year windows.
} 
business returns decay over time to the mean. Specifically, the dependent variable we use is the ROA of business $i$ operating in year $t\left(\mathrm{ROA}_{i t}\right)$. It is regressed on a constant, a 1-year lagged value of the dependent variable $\left(\mathrm{ROA}_{i t-1}\right)$, a year counter ranging from 1 (in 1979) to 19 (in 1997) $\left(\mathrm{YEAR}_{t}\right)$, a term interacting lagged ROA and the year counter $\left(\mathrm{ROA}_{i t-1} * \mathrm{YEAR}_{t}\right)$, a measure of annual GDP growth $\left(\mathrm{GDPG}_{t}\right)$, a measure of annual inflation $\left(\mathrm{INF}_{t}\right)$, and an error term $\left(\varepsilon_{i t}\right)$.

With this model, the coefficient estimate of the 1-year lagged ROA $\left(\mathrm{ROA}_{i t-1}\right)$ generally falls between 0 and 1.00 , with a value near 1.00 indicating that there is little if any decay in abnormal returns from the last to the current year. The coefficient estimate on the year counter $\left(\mathrm{YEAR}_{t}\right)$ indicates linear time trends in business returns. The key term in this model is the interaction term $\left(\mathrm{ROA}_{i t-1} * \mathrm{YEAR}_{t}\right)$ the coefficient estimate which indicates whether the rate of decay in abnormal returns exhibits any linear time trends over the study period. Consistent with Hypothesis 1, we predict that this interaction term will exhibit a significant and negative coefficient estimate, indicating an increasing rate of decay in abnormal returns over the 1979-97 period. Over time, the previous year's ROA for a business should explain less of the current year's ROA for the same business.

To control for macroeconomic conditions that may also affect the degree to which abnormal returns persist, we include two control variables. Economic growth $\left(\mathrm{GDPG}_{t}\right)$ is measured using the rate of growth in the gross domestic product on an annual basis. We also control for the inflation rate $\left(\mathrm{INF}_{t}\right)$ using the percentage change in the consumer price index.

The data used for this analysis are substantially the same as with the variance components analysis, with one difference. The structure of our analysis necessitated that we exclude all businesses that did not report data in the previous year. Thus, our analysis includes all businesses from 1979 to 1997 that reported financial data in the previous year. The resulting sample comprises 89,937 observations.

\section{Mortality (hazard rate) analysis}

To formally test Hypothesis 2, we resort to a proportional hazard rate model (Lin and Wei, 1989) explaining the likelihood that a business will disappear (exit) from an industry $I$ in the next year.
We operationalize business mortality as a dummy taking the value of 1 if the business unit does not survive in the following year. Our IVs include a year counter ranging from 1 (in 1978) to 20 (in 1997) $\left(\right.$ YEAR $\left._{t}\right)$, a measure of annual GDP growth $\left(\mathrm{GDPG}_{t}\right)$, the value of mergers and acquisitions in industry $i$ of year $t\left(\mathrm{VM} \& \mathrm{~A}_{t}\right)$, industry $i$ 's density in year $t$ (INDDENS ${ }_{i t}$ ) and its quadratic transformation (INDDENS ${ }_{i t}^{2}$ ). Consistent with Hypothesis 2, we predict that the coefficient estimate for the year counter $\left(\mathrm{YEAR}_{t}\right)$ term will be significant and positive, indicating an increasing likelihood of mortality (exit) over the 1978-97 period. Over time, increasing hypercompetition will increase the likelihood of business mortality.

To control for other effects on business mortality we include terms to account for macroeconomic and industry-specific conditions. We include economic growth $\left(\mathrm{GDPG}_{t}\right)$ again to control for economic conditions possibly affecting the likelihood of business failure. We also include the annual dollar volume of U.S. mergers and acquisitions $\left(\mathrm{VM} \& \mathrm{~A}_{t}\right)$ as activity in this field may also change the likelihood of industry exit. Finally, following Hannan and Freeman (1988), we control for industry density (INDDENS ${ }_{i t}$ ) using a count value of businesses in the appropriate 4-digit SIC. We also include the quadratic form of this term $\left(\right.$ INDDENS $_{i t}^{2}$ ) to allow us to capture a possible nonlinear, inverted U-shaped density effect. The base control variables are standardized with a mean value of 0 and a standard deviation of 1 to limit the effect of multicollinearity on the results, and to allow for parameter estimates that are of a magnitude easily represented in the results table.

The sample includes all businesses in our sample from 1978 to 1996. We exclude all observations from the final year in our sample, 1997, since we are unable to determine if that business survived in the following year. This results in a total sample of 107,979 observations.

\section{Industry stability (dynamism) and munificence analyses}

To formally test Hypotheses 3 and 4, we take a within-subjects regression model approach. This amounts to a regression of industry dynamism (munificence) on individual industry dummies and three of four possible time periods in our sample for comparison of overall dynamism and munificence scores. As a preliminary step, we follow 
previous research (e.g., Dess and Beard, 1984; Sutcliffe, 1994) in calculating munificence and dynamism for each 4-digit SIC industry operating in four different 5 -year panels of our data (1978-82, 1983-87, 1988-92, and 1993-97). To compute these indexes, we first regress industry sales, capital expenditures, and assets on a variable representing the years in the 5-year panel. We then divide the standard error of each regression by the mean value of each dependent variable. Taking the average of these three resulting numbers yields a composite measure of the level of dynamism in the industry in each year of the four 5-year periods examined. We measure munificence using the regression coefficients for each of the regressions noted above. As with the dynamism variable, we average the coefficients for the three indexes to construct a composite measure of the level of industry munificence in each year of the four 5year periods examined. This measure provides an indication of the degree of growth or decline within an industry over that period.

With these dependent variable measures for the within-subjects regression, we turn next to the IVs. They include dummies for each industry (908) less one in our analysis. The industry dummy variables control for systematic, industry-specific differences in dynamism and munificence leaving for analysis over time economy-wide trends in each dependent variable. We then add timeperiod dummies for three of the four time panels. Specifically, we exclude the dummy for the final time period (1993-97). By regressing the annual measure of dynamism (munificence) on these time period dummies, we can obtain coefficient estimates for comparison with each other and against the omitted time period. Hypothesis 3 will be supported if we find that the parameter estimates for all of the periods dummied out in the dynamism regression are negative (relative to the omitted final time period) and significant; the greatest negative estimate should be in the earliest time period, thus indicating a positive trend for dynamism over the period studied. Hypothesis 4 will be supported if the coefficients for the dummied periods in the munificence regression exhibit positive signs (relative to the omitted final time period) that are significant; the earliest time period should provide the largest positive estimate, thus indicating a negative trend for munificence over the period studied.

\section{RESULTS}

\section{Variance components model results}

As noted earlier, the VC analyses presented here provide us with preliminary insight on our first proposition regarding changes in the nature of business performance in the 1980s and 1990s. At the heart of the hypercompetition perspective is the implication that businesses are less able to sustain competitive advantages as markets become less stable. If there were a hypercompetitive shift across a broad range of markets, then we would expect to see the importance of unstable factors shaping business performance increase over time. In terms of our variance components model, this implies that the percentage of variance attributable to stable (unstable) effects in total decrease (increase) as we progress from earlier to later four-year windows.

Table 1 reports percentages of variance attributable to various effects on business-unit performance modeled in successive 4-year windows from 1978 to 1997. Overall, the results in Table 1 are not consistent with our research propositions about decreasing stability in markets and businesses. Total stable effects $\left(\sigma_{\alpha}^{2}+\sigma_{\beta}^{2}+\sigma_{\phi}^{2}\right)$ do decrease from 71.3 percent in $1978-81$ to as low as 63.7 percent in the mid-1980s (1985-88). Then, however, total stable effects increase again in to approximately 68 percent throughout the 1990s. Variance in business-unit ROA linked to stable effect exhibits neither steady decrease as the proposition of increasing hypercompetition suggests, nor steady increase. Instead, we see fluctuation in total stable effects and total unstable effects $\left(\sigma_{\gamma}^{2}+\sigma_{\delta}^{2}+\sigma_{\lambda}^{2}+\sigma_{\varepsilon}^{2}\right)$. This pattern of fluctuation is illustrated in Figure 1.

In Figure 1, the extent of fluctuation between total stable and unstable effects does not appear to be substantial over the entire 20-year period of study. Additionally, the percentage of variance attributable to unstable effects peaks in the mid- to late-1980s, resulting in a pattern that does not suggest a consistent pattern of change in the percentage of variance attributed to unstable effects over the 1978-97 period. Overall, these variance components results yield little support for Proposition 1 's claim that the stability of business performance has decreased in 1980s and 1990s. 


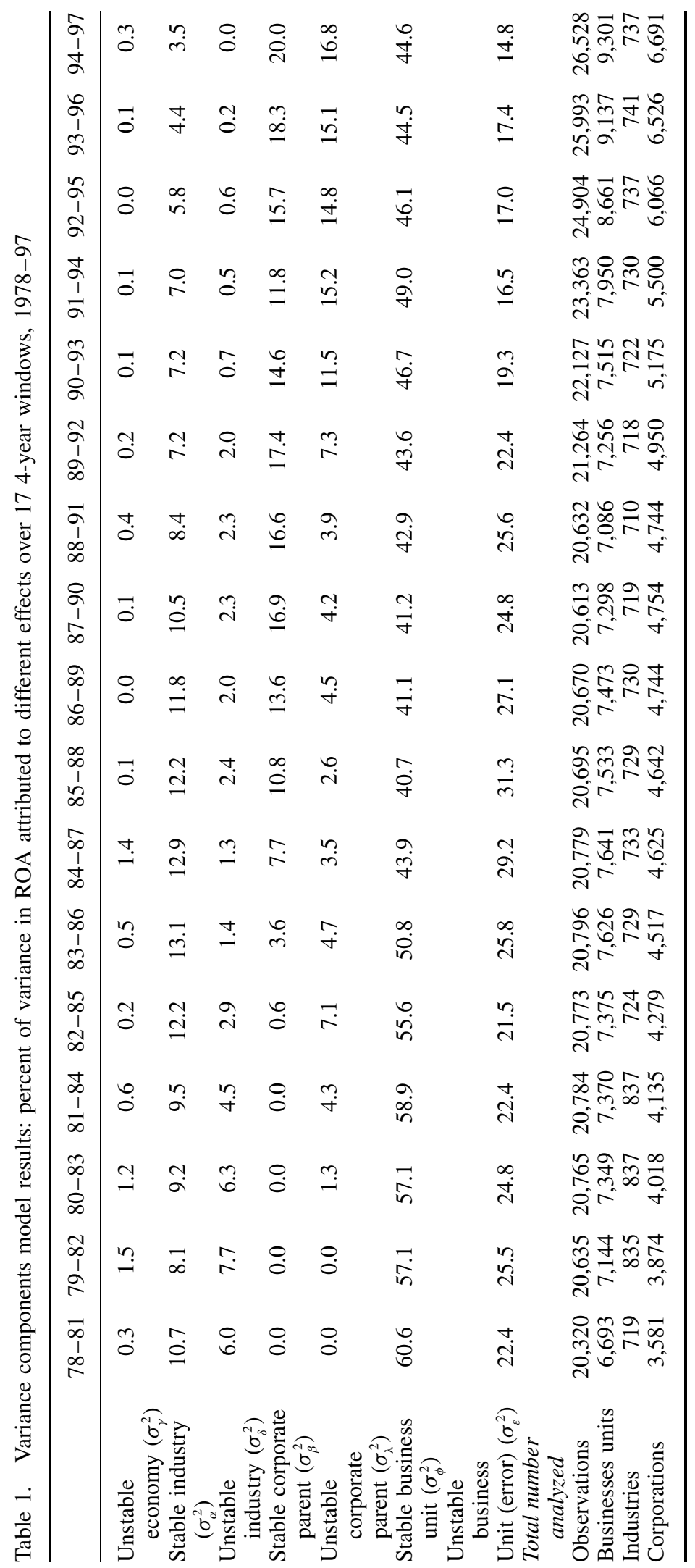




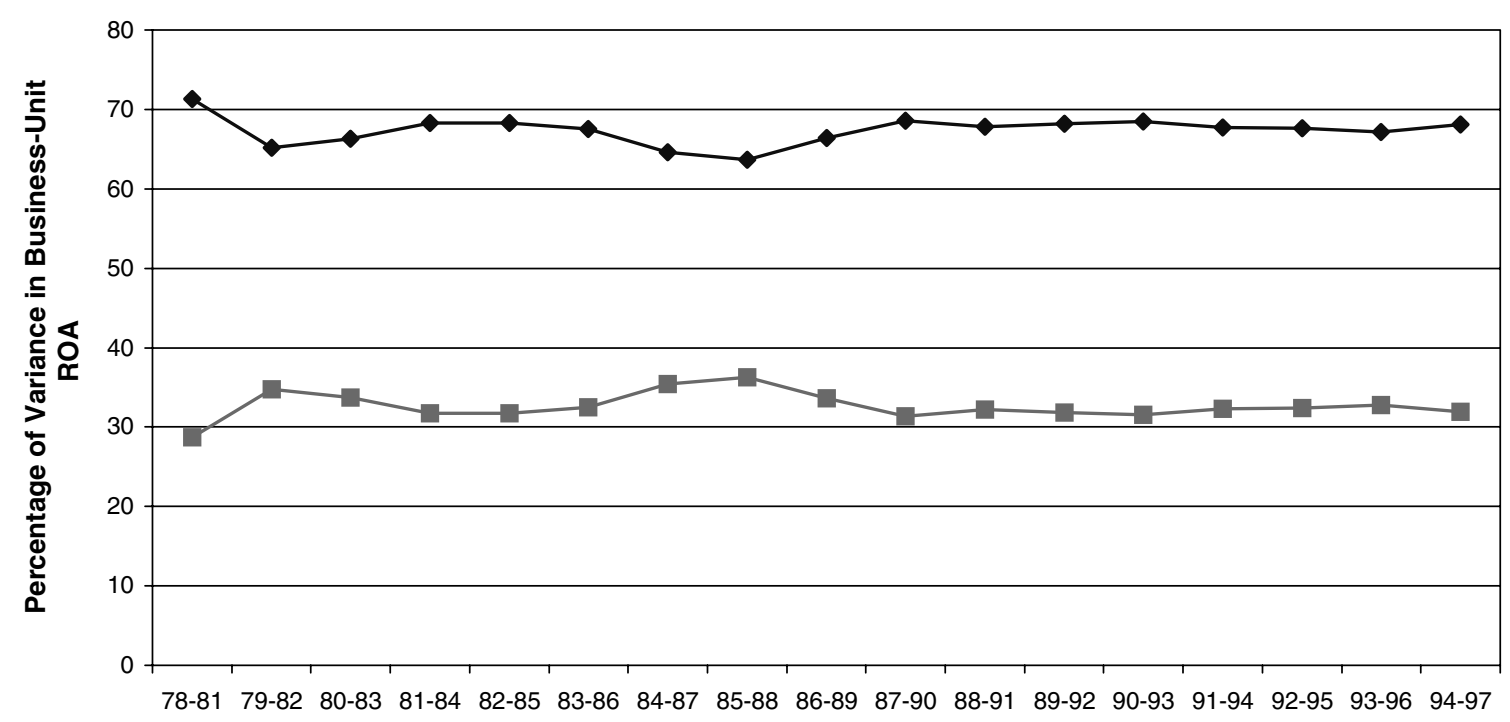

Four-Year Moving Window

Total Stable Effects

Figure 1. Stable and unstable effects on variance in business-unit ROA over 17 4-year windows, 1978-97

\section{Autoregressive model results}

Results from the autoregressive analyses are reported in Table 2. Similar to the VC analysis results, they provide no indication of a significant increase in instability in business-unit performance over the period of study. Consistent with Jacobsen (1988), we find that the base autoregressive coefficient is significant, positive, and less than one, indicating that business performance exhibits significant time trends and that abnormal business returns tend to regress to the mean over time. Recall that Hypothesis 1's support depends on there being a significant increase in the decay rate of abnormal business returns over the period studied; in this case, it means a significant and negative coefficient estimate for the interaction term included in the expanded autoregressive model in Table $2\left(\mathrm{ROA}_{i t-1} * Y E A R_{t}<0\right)$. The hierarchical regression results in the second column of Table 2 suggest that the estimate for the interaction term, in contrast to Hypothesis 1, is not significantly different from zero $(F=0.05, p=0.82)$. This indicates no evidence for a systematic change in the decay rate over the period studied.

To assess the possibility of nonlinear changes in the decay rate, we conducted a post hoc analysis. We eliminated the year counter term $\left(\mathrm{YEAR}_{t}\right)$,
Table 2. Autoregressive model results: impact of time (year) on lagged business-unit ROA's relationship to current period ROA, 1978-97

\begin{tabular}{|c|c|c|}
\hline $\begin{array}{l}\text { Independent } \\
\text { variables }\end{array}$ & $\begin{array}{l}\text { Base } \\
\text { model }\end{array}$ & $\begin{array}{c}\text { Model } \\
\text { with the } \\
\text { interaction } \\
\text { term }\end{array}$ \\
\hline Constant & $\begin{array}{c}0.0178^{* *} \\
(0.0017)\end{array}$ & $\begin{array}{l}0.0179^{* *} \\
(0.0018)\end{array}$ \\
\hline $\begin{array}{l}\text { 1-year lagged returns } \\
\left(\mathrm{ROA}_{i t-1}\right)\end{array}$ & $\begin{array}{l}0.6742^{* *} \\
(0.0023)\end{array}$ & $\begin{array}{l}0.6731^{* *} \\
(0.0053)\end{array}$ \\
\hline Year counter $\left(\mathrm{YEAR}_{t}\right)$ & $\begin{array}{c}-0.0004^{* *} \\
(0.0001)\end{array}$ & $\begin{array}{c}-0.0004^{* *} \\
(0.0001)\end{array}$ \\
\hline $\begin{array}{l}\text { GDP growth rate } \\
\left(\mathrm{GDPG}_{t}\right)\end{array}$ & $\begin{array}{l}0.0029^{* *} \\
(0.0002)\end{array}$ & $\begin{array}{l}0.0029^{* *} \\
(0.0002)\end{array}$ \\
\hline Inflation $\left(\mathrm{INF}_{t}\right)$ & $\begin{array}{l}0.0017^{* *} \\
(0.0002)\end{array}$ & $\begin{array}{l}0.0017^{* *} \\
(0.0002)\end{array}$ \\
\hline $\begin{array}{l}\text { Interaction term } \\
\left(\mathrm{ROA}_{i t-1}{ }^{*} Y E A R_{t}\right)\end{array}$ & & $\begin{array}{c}0.0001 \\
(0.0004)\end{array}$ \\
\hline$F$ & $21,941.4^{* *}$ & $17,553.0^{* *}$ \\
\hline$R^{2}$ & 0.4939 & 0.4939 \\
\hline Incremental $F$ & & 0.05 \\
\hline Incremental $R^{2}$ & & 0.0000 \\
\hline$N$ & 89,937 & 89,937 \\
\hline
\end{tabular}

${ }^{* *} p<0.01$

${ }^{\text {a }}$ Standard error terms appear in parentheses. 


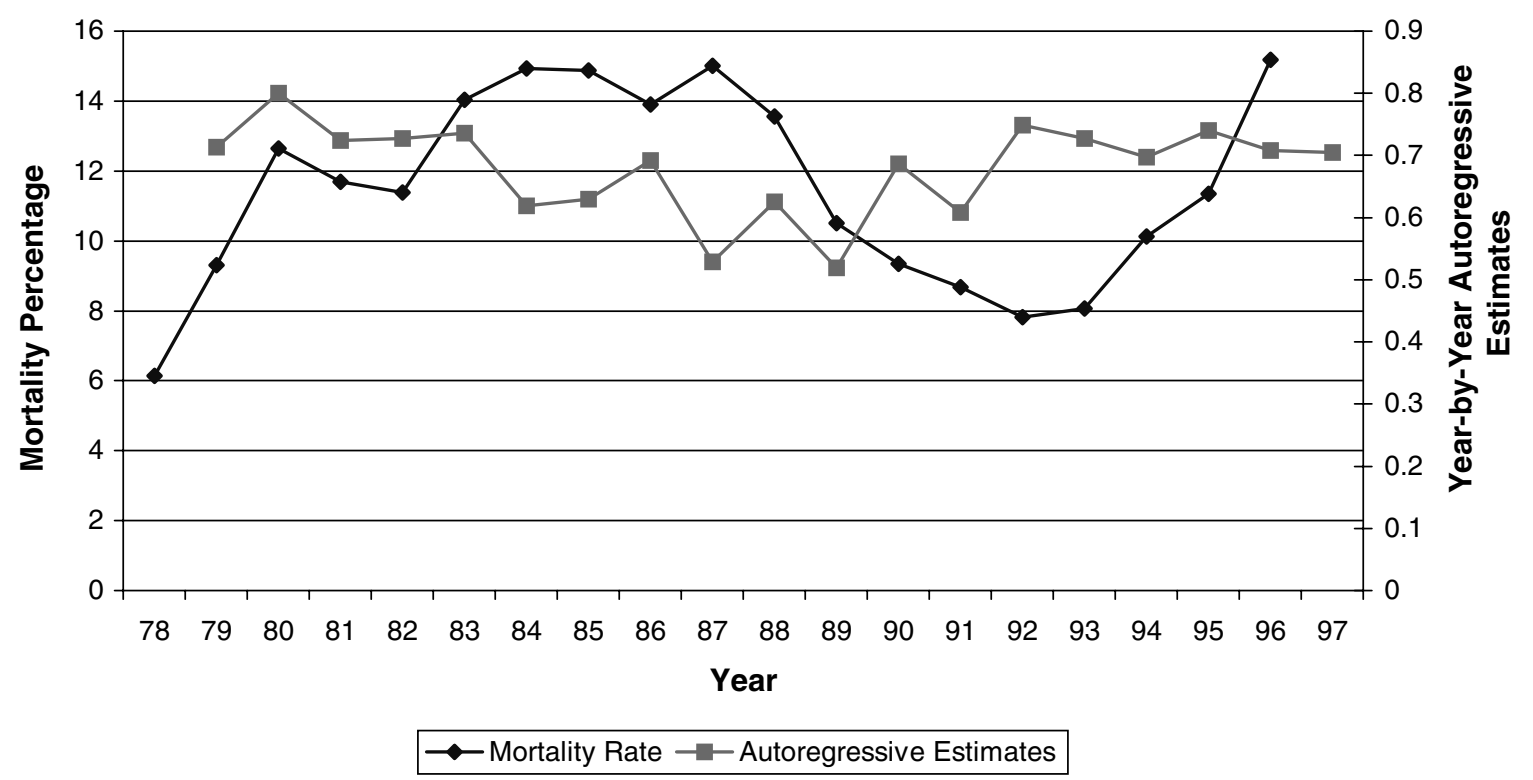

Figure 2. Annual mortality rates of business segments and year-by-year autoregressive estimates

replacing it with year dummies for each year in the 1979-97 time period except the final year, 1997. We also added terms interacting these dummies with 1-year lagged business returns $\left(\mathrm{ROA}_{i t-1}\right)$. The parameter estimates for these interaction terms now reflect differences in the decay rate between each year and the year interaction omitted from the analysis. Consistent with the linear analysis, we find in this post hoc regression analysis no consistent pattern in the parameter estimates for the interaction terms, although, as a set, the year indicator variables are significant $(F=55.14, p<$ $0.01)$. Instead, we find a fluctuating pattern where the decay rate is significantly higher $(p<0.05)$ in 1997 than in some prior years $(1980,1983$, 1992, and 1995), but also significantly lower than in other years $(1984,1985,1987,1988,1989$, and 1991), and not significantly different from several years $(1979,1981,1982,1986,1990,1993,1994$, and 1996). The most striking finding we see in this pattern is that the decay rate appears to be consistently higher in the mid- to late-1980s than the remainder of the sample, evidenced by the trough in the autoregressive estimates plotted in Figure 2. Thus, consistent with our earlier variance components analysis, we find a pattern suggesting that the degree to which businesses are able to sustain abnormal profits was lower in the mid- to late-1980s than in either the earlier or later time periods included in the analysis. This pattern is also inconsistent with the prediction in Hypothesis 1 of generally increasing instability of business returns in the 1980s and 1990s.

\section{Mortality analysis results}

Table 3 reports results from the proportional hazards (mortality) analyses. Again, these analyses provide little evidence supporting Hypothesis 2's prediction of increasing business mortality in the 1980s and 1990s. We expected to find the parameter estimate for the year variable in our hazard rate model to be positive and significant, indicating an increase in the mortality rate over time. Instead, the parameter estimate is negative and significant $(p<0.01)$, suggesting that the mortality rate decreased during the time period of examination. However, the statistical significance of parameter estimate in the hazard rate model is almost certainly the consequence of an extremely large sample size $(N=107,979)$ rather than any unmistakable trend in the data. Given the small value of the parameter estimate and the relatively modest $\chi^{2}$ statistic, a more conservative interpretation of these results suggests that there is no linear trend of practical significance from 1978 to 1997. Business mortality (exit from an industry) exhibits no upward trend over time across the broad sample of businesses we analyzed.

Strat. Mgmt. J., 24: 261-278 (2003) 
Table 3. Hazard rate model results: impact of time (year) on likelihood of business-unit mortality (exit from industry), 1978-97

\begin{tabular}{lcc}
\hline Variables & $\begin{array}{c}\text { Control } \\
\text { model }\end{array}$ & $\begin{array}{c}\text { Full } \\
\text { model }\end{array}$ \\
\hline GDP growth rate $_{\left(\text {GDPG }_{t}\right)}$ & -0.0012 & -0.0042 \\
Industry M\&A $_{\text {value }\left(\mathrm{VM} \& \mathrm{~A}_{i t}\right)}^{(0.0037)}$ & $(0.0038)$ \\
Industry density & $0.0205^{* *}$ & $0.0356^{* *}$ \\
(INDDENS $\left._{i t}\right)$ & $(0.0044)$ & $(0.0056)$ \\
Industry density $^{2}$ & $\left(0.0299^{* *}\right.$ & $-0.0277^{* *}$ \\
(INDDENS $\left._{i t}^{2}\right)$ & $0.0074^{* *}$ & $(0.0055)$ \\
Year counter & $(0.0021)$ & $0.0071^{* *}$ \\
$\left(\right.$ YEAR $\left._{t}\right)$ & & $(0.0021)$ \\
$\chi^{2}$ & & $-0.0030^{* *}$ \\
Incremental $^{2}$ & $53.58^{* *}$ & $(0.0007)$ \\
$N$ & & $71.39^{* *}$ \\
& 107,979 & $17.81^{* *}$ \\
\hline
\end{tabular}

${ }^{* *} p<0.01$

a Standard errors in parentheses.

To gain a better sense of any trends in mortality during some part of the 1978-97 period, we plotted the likelihood of business mortality from year to year in Figure 2. It reveals a fluctuating pattern similar to the ones we observed with variance components and autoregressive analyses. The mortality rate starts out at 6 percent in 1978, peaks in the mid- and late-1980s at approximately 15 percent, drops down in the early 1990s, and rises again in the final year to 15 percent. This pattern follows the pattern of total stable variance components in Figure 1 and mirrors the year-to-year autoregressive pattern in Figure 2. Again, there is no consistent pattern suggesting that mortality rates have increased generally throughout the 1980s and 1990s. Thus, we find no support for Hypothesis 2.

\section{Industry stability (dynamism) and munificence results}

Recall that our basic research propositions about hypercompetition concerned both decreases in the stability of business performance and market stability. While results from our previous analyses have directly addressed the proposition regarding the stability of business performance, they have only indirectly addressed market stability issues.

Tests for changes in industry dynamism and munificence provide additional insight into the proposition that markets have become less stable due to increasing hypercompetition in the $1980 \mathrm{~s}$ and 1990s. With Hypotheses 3 and 4 we argue that, if there has been a hypercompetitive shift during the period of observation, the level of industry dynamism should have increased and the level of industry munificence should have decreased over the study period. Results from our analysis of industry dynamism listed in Table 4 do not support Hypothesis 3. As a preliminary step, we first estimated an equation using industry dummy variables only. We then added indicator variables for three of our four 5-year data windows (omitting the final window running from 1993 to 1997). Hypothesis 3 predicts that the time indicator variables should all be negative, with the largest magnitude in the earliest time period. While the addition of the time indicator variables does statistically improve the regression analysis $(F=3.16$, $p<0.05)$, the signs of the parameter estimate are not what we anticipated and the explanatory value of adding these variables is quite low (incremental $\left.R^{2}=0.0025\right)$. The results in Table 4 indicate that dynamism was higher in Time Period $2\left(1983-87_{t}\right)$ than in Time Period $4\left(1993-97_{t}\right)(p<0.01)$. Further examination indicates that dynamism is higher in Time Period $2\left(1983-87_{t}\right)$ than in Time Period $1\left(1978-82_{t}\right)(p<0.05)$. As with the earlier analyses, we find a fluctuating pattern, with conditions indicating greater dynamism in the mid- to late1980s compared to time periods before and after. These results do not support a generally increasing trend in dynamism predicted by Hypothesis 3. This finding is similar to Castrogiovanni's (2002) conclusion that dynamism had not increased in a sample of 88 manufacturing industries from the late 1960 s to the early 1990 s.

Similarly, Table 4's results on industry munificence yield little support for Hypothesis 4. Although the indicator variable for Time Period 3 $\left(1988-92_{t}\right)$ is significant, we are unable to interpret the pattern of results for the period indicator variables since the overall equation for industry munificence is not statistically significant. Thus, we are unable to conclude that there are any significant differences in industry munificence across the time periods examined. This finding can be contrasted with Castrogiovanni's (2002) finding that munificence had decreased in a more constrained sample of 88 manufacturing industries over a period from 1967 to 1992 . Our findings for 
munificence and dynamism suggest that Proposition 2's claim of increasing instability in markets during the 1980s and 1990s lacks support.

\section{DISCUSSION AND CONCLUSION}

\section{Summary of central findings}

The aim of this study is not to diminish the importance of factors associated with the hypercompetition perspective on business strategy. As previous research (e.g., Rumelt, 1991; Chang and Singh, 2000) and, indeed, our results suggest, a substantial portion of the variance in business profitability can be attributed to unstable, often ephemeral effects regardless of the time period studied. Unstable effects, for example, explain 25-35 percent of the total variance in business ROA across the 1978-97 period. Accordingly, management of dynamic environments and innovative capabilities remains important to any explanation of persistent performance differences among businesses, and continues to merit substantial academic attention (Eisenhardt and Martin, 2000).

Our study asked a different question implied by certain proponents of the hypercompetition perspective. Has the effect of such factors increased in the recent past? On the whole, our results suggest not. The relative importance of hypercompetitive assumptions about markets, business strategy, and performance in the late 1990s appears to be much the same as it was in the late 1970s and early 1980s. If anything, hypercompetition may exhibit cycles of increase and decrease as described by researchers examining this trend in individual markets (e.g., Gimeno and Woo, 1996; Bogner and Barr, 2000).

So how do we explain the apparent mismatch between the contentions of the proponents of a general hypercompetitive shift and the unsupportive, sometimes contrary evidence we found? At least two responses to this question are briefly examined. First, the mismatch may be the result of timing. We noted in our discussion of results that focus on a selected time period in our study might, on its own, lead to a conclusion of persistent increase in hypercompetition. Trends evidenced in Figures 1 and 2, for example, might easily lead researchers to just such a conclusion if their time period of study were limited to, say, 1978-88. It is, perhaps, more than coincidental that much of the earlier literature associated with contentions of generally increasing hypercompetition relies on case studies and statistical analysis of larger data sets that conclude in the 1980s or early 1990s (e.g., MacMillan, 1989; D'Aveni, 1994, 1995; Thomas, 1996; Hamel and Prahalad, 1994).

A second response to this question has less to do with research timing and more to do with researcher hindsight. Research on decision making has demonstrated that individuals have a propensity to suffer from hindsight bias (Fischhoff, 1975; Wood, 1978). This body of research indicates that individuals view situations in retrospect very differently than they do in prospect. In viewing a historical chain of events, people tend to see a clear and logical causal pattern, concluding that the chain of events was clearly predictable. In contrast, they show much less confidence in predicting the outcomes of similar situations for which they don't yet know the outcome. In other words, individuals perceive past events as more logical and stable than they do the future. This behavioral attribute may explain both managers' and researchers' perceptions of increasing instability in current time periods.

Mintzberg $(1991,1994)$ reminds us that perceptions of increasing environmental instability often derive more from cognitive biases-hindsight and/or egotistical in nature-than from any real change in the environment. More than a decade ago, he was chiding strategy researchers for 'groundless escalation' of vocabulary describing increasing 'turbulence' that was more desirable myth than ascertainable fact (Mintzberg, 1991: 464). As he later concluded, '[T]urbulence turns out to be a condition, not of the outside environment, but of our inner selves. It's an imagined condition: We glorify ourselves by describing our own times as turbulent ... While "now" has always been turbulent, "before" had somehow always magically stabilized, the very same "before" that used to be "turbulent" (Mintzberg, 1994: 7).

If such bias is at work in the case of hypercompetition, then this bias is not new. Claims of increased change and instability in the 'current' environment are a common refrain in management literature predating the 1980s. For example, from the 1970s, we find organization theorists remarking that '[W]e who live in this latter part of the twentieth century are witnesses to remarkable, rapid, 
Table 4. Industry munificence and instability (dynamism) model results: impact of time (comparison of four windows) of industry munificence and instability (dynamism), 1978-97 a,b

\begin{tabular}{|c|c|c|c|c|}
\hline \multirow[t]{2}{*}{ Independent variables } & \multicolumn{2}{|c|}{ Industry munificence } & \multicolumn{2}{|c|}{ Industry dynamism } \\
\hline & Controls only & $\begin{array}{l}\text { Including time } \\
\text { periods }\end{array}$ & Controls only & $\begin{array}{l}\text { Including time } \\
\text { periods }\end{array}$ \\
\hline Constant & $\begin{array}{c}0.2101 \\
(0.2092)\end{array}$ & $\begin{array}{c}0.2168 \\
(0.2078)\end{array}$ & $\begin{array}{c}0.0833 \\
(0.0637)\end{array}$ & $\begin{array}{c}0.0817 \\
(0.0637)\end{array}$ \\
\hline Time period $1\left(1978-82_{t}\right)$ & & $\begin{array}{c}-0.0067 \\
(0.0127)\end{array}$ & & $\begin{array}{c}0.0016 \\
(0.0039)\end{array}$ \\
\hline Time period $2\left(1983-87_{t}\right)$ & & $\begin{array}{c}-0.0106 \\
(0.0117)\end{array}$ & & $\begin{array}{l}0.0104^{* *} \\
(0.0036)\end{array}$ \\
\hline Time period $3\left(1988-92_{t}\right)$ & & $\begin{array}{c}-0.0593^{* *} \\
(0.0116)\end{array}$ & & $\begin{array}{c}0.0047 \\
(0.0036)\end{array}$ \\
\hline$F$ & 0.93 & 0.98 & $2.22^{* *}$ & $2.23^{* *}$ \\
\hline$R^{2}$ & 0.3247 & 0.3369 & 0.5327 & 0.5352 \\
\hline Adjusted $R^{2}$ & -0.0226 & -0.0060 & 0.2923 & 0.2949 \\
\hline Incremental $F$ & & $10.77^{* *}$ & & $3.16^{*}$ \\
\hline Incremental $R^{2}$ & & 0.0122 & & 0.0025 \\
\hline$N$ & 2677 & 2677 & 2677 & 2677 \\
\hline
\end{tabular}

and even, for some of us, overwhelming change' (Marguiles and Wallace, 1973: 1). From the 1950s, we read from a technology management academic contending that ' $[\mathrm{C}]$ hange confronts all of us. We are living in a time of accelerating change ...' (LaPierre, 1958: 27). And from the 1930s, we learn of Elton Mayo, an industrial relations professor, noting 'the vastly accelerated speed of change that man's science and technology have brought,' and warning 'that man must learn to adjust, especially in industry, to these changes' (Daffern, 1960: xiii-xiv).

\section{Implications for management research and practice}

We see several implications to draw from this study for management research and practice. We briefly note two. One important implication for research is that management scholars should take care in simply assuming that hypercompetitive trends are becoming more pronounced, either generally or in specific business settings of interest. Those assumptions may be based on evidence gleaned from 'aberrant' time periods, may be based on some hindsight bias, or may be based merely on theoretical fashions and fads among scholarly colleagues (Abrahamson, 1991).
Another important implication to draw from this study is that the strategy field is now and will likely continue to be rather heterodox in its theoretical perspectives. We find evidence that stable factors at industry, corporate, and business-unit levels, as well as unstable factors, all significantly affect business performance. IO, corporate, RBV, and dynamic perspectives all have the potential to contribute to any explanation of business performance. Researchers examining the performance of organizations and practicing managers should be aware of and address industry-, corporate-, business-, and other-level factors that together drive business success or failure.

\section{Limitations and future research}

It would be hypocritical to counsel skepticism in reviewing scholarly research if we did not voice any criticism of our own study. Our study sought to describe what we saw as a central contention among proponents of hypercompetition-that instability in markets and business performance has generally increased in the recent past. We then investigated this contention and found empirical support for it wanting. Our study is open to criticism about the way in which we characterize hypercompetition and describe its 
likely antecedents and outcomes. Future research might seek a more detailed review of the hypercompetition-related perspectives to describe and test more subtle differences of viewpoint about the nature of business strategy and performance in volatile environments. Our own study suggests that minority views characterizing hypercompetition as cyclical (e.g., Gimeno and Woo, 1996) or contingent (e.g., Ang and Cummings, 1997) phenomena merit closer examination.

We conclude from the results of our study that there is little evidence that markets have become more hypercompetitive in the late 1990s than they were in the late 1970s. We conjecture that more volatile periods in the 1980s may have been a temporary consequence of policies promoting substantial industry deregulation and trade liberalization in the U.S. economy. As such, we believe the pattern we found may reflect a punctuated equilibrium process (Tushman and Romanelli, 1985) with exogenous shocks pushing firms and markets temporarily into periods of enhanced volatility. Additionally, at a lower level of analysis, individual industries may move in and out of periods of hypercompetition due to endogenous forces at work within each market. As Gimeno and Woo (1996) note, firm actions that lead to changes in the degree of strategic heterogeneity and/or market overlap may induce competitive escalation or deescalation. Bogner and Barr (2000) offer a slightly different perspective, arguing that the sensemaking practices employed by managers within markets can either amplify or attenuate pressures leading to hypercompetition. Thus, both exogenous and endogenous forces may affect behavior within industries prompting cycles of increasing and decreasing market stability.

However, another plausible interpretation of results reported in this study notes a confluence of changes rendering markets more volatile and compensating changes in business strategy by executives. A dynamic capabilities perspective on strategy (Eisenhardt and Martin, 2000) suggests that adroit managers may develop and maintain certain assets and capabilities with competitive value across a broad range of market scenarios. In the heightened uncertainty engendered by hypercompetition, managers may have learned to make investments in plant, property, equipment, people and/or knowledge with more flexible dimensions. Trends indicating increased hypercompetition in the early and mid-1980s followed by more stability in the 1990s may reflect such a compensating strategy change in many businesses.

While this is a plausible alternative interpretation of our results, we think it unlikely. First, as discussed earlier in the paper, increasing the number of decisions that businesses must make regarding strategic factors shaping their future performance is likely to lead to greater instability in performance patterns. As our stylized example of 100 businesses suggested, any individual business's ability to make choices that perpetuate stable performance would need to increase substantially as its environment becomes progressively more unstable to generate the same stability in performance over time.

Critics might still contend that businesses can nonetheless adjust quickly to this new competitive landscape. This leads to a second response. The implicit assumption here is that most, if not all, businesses responded in an effective and timely way to a fundamental shift in their operating environment. Applied across the broad range of business activities in the U.S. economy, this assumption strikes us as ambitious - perhaps too ambitious, given the difficulty organizations have in undertaking such fundamental changes (e.g., March and Simon, 1958; Hannan and Freeman, 1977, 1984), the frequency with which businesses suffer from the inability to accurately perceive shifts in their environment (Zajac and Bazerman, 1991), the significant organizational commitments businesses often make that inhibit their ability to change course (Ghemawat, 1991), and the differential rates of friction in making change speedily due to time impactedness (Dierickx and Cool, 1989).

Third, articulation of the dynamic capabilities perspective by strategy scholars is recent (Teece et al., 1997), and many of its empirical implications still await testing. In the meanwhile, researchers continue to argue that many managers remain 'mired' in the mindset of environmental stability and sustainable advantage (Hamel, 2000; Eisenhardt and Martin, 2000). Another way to read this past (and current) state of the dynamic capabilities view is that it is still not widespread either in the Academy or in practice. Accordingly, we would not expect it to be broadly utilized by managers as a compensating 'remedy' to the 'condition' of advancing hypercompetition across the U.S. economy.

In the end, we do not test for evidence supporting or rejecting this alternative explanation, so our 
reasoning is ultimately conjectural, but then the same might be said of critics seeking to minimize the implications of our findings. Future researchers may wish to explore this issue with tests designed to uncover the compensating impact of dynamic capabilities across multiple industries purported to be experiencing increasing hypercompetition.

With this in mind, we believe that our study makes a compelling case for the lack of widespread evidence to support the contention made by many in the strategy field that markets are, in general, any more unstable now than they were in the recent past. What managers face today in terms of hypercompetition is largely the 'same as it ever was.' Similarity between past and present should not stifle further research into the causes and consequences of hypercompetitive forces. On the contrary, understanding how markets apparently experience cycles of increase and decrease in turbulence and how businesses respond should prompt substantial future research with valuable implications for practice.

\section{ACKNOWLEDGEMENTS}

We thank Charles Hadlock for his help in collecting the data used in this study. We would also like to thank Phil Bromiley, Susan McEvily, William McEvily, David Deephouse, and the anonymous $S M J$ referees for their insightful comments and suggestions on earlier versions of this manuscript. Support for this research from the Fletcher School of Law and Diplomacy's Hitachi Center for Technology and International Affairs is gratefully acknowledged.

\section{REFERENCES}

Abrahamson E. 1991. Managerial fads and fashions: the diffusion and rejection of innovations. Academy of Management Review 16: 586-612.

Alavi M, Yoo Y, Vogel DR. 1997. Using information technology to add value to management education. Academy of Management Journal 40: 1310-1333.

Amit R, Zott C. 2001. Value creation in e-business. Strategic Management Journal, Special Issue 22(6-7): 493-520.

Ang S, Cummings LL. 1997. Strategic response to institutional influences on information systems outsourcing. Organizational Science 8: 235-256.

Argote L. 1999. Organizational Learning. Kluwer: Boston, MA.
Bain JS. 1956. Barriers to New Competition. Harvard University Press: Cambridge, MA.

Barney JB. 1991. Firm resources and sustained competitive advantage. Journal of Management 17: 99-120.

Baum JA, Oliver C. 1991. Institutional linkages and organizational mortality. Administrative Science Quarterly 36: 187-218.

Bettis RA, Hitt MA. 1995. The new competitive landscape. Strategic Management Journal, Summer Special Issue 16: 7-20.

Bogner WC, Barr PS. 2000. Making sense in hypercompetitive environments: a cognitive explanation for the persistence of high velocity competition. Organization Science 11: 212-226.

Brown SL, Eisenhardt K. 1998. Competing on the Edge. Harvard Business School Press: Boston, MA.

Brush T, Bromiley P, Hendrickx M. 1999. The relative influence of industry and corporation on business segment performance: an alternative estimate. Strategic Management Journal 20(6): 519-547.

Burke LA. 1997. Developing high-potential employees in the new business reality. Business Horizons 40: $18-24$.

Castrogiovanni G. 1991. Environmental munificence: a theoretical assessment. Academy of Management Journal 16: 542-565.

Castrogiovanni G. 2002. Organization task environments: have they changed fundamentally over time? Journal of Management 28: 129-150.

Chandler AD. 1962. Strategy and Structure. Harvard University Press: Cambridge, MA.

Chang S-J, Singh H. 2000. Corporate and industry effects on business unit competitive position. Strategic Management Journal 21(7): 739-752.

Daffern GN. 1960. Management Development in a Changing World. Simmons-Boardman: New York.

D’Aveni RA. 1994. Hypercompetition. Free Press: New York.

D'Aveni RA. 1995. Coping with hypercompetition: utilizing the new 7S's framework. Academy of Management Executive 9: 45-57.

Dess GC, Beard DW. 1984. Dimensions of organizational task environments. Administrative Science Quarterly 9: 52-73.

Dierickx I, Cool K. 1989. Asset stock accumulation and sustainability of competitive advantage. Management Science 35(12): 1504-1514.

Eisenhardt KM, Martin JA. 2000. Dynamic capabilities: What are they? Strategic Management Journal, Special Issue 21(10-11): 1105-1121.

Fischhoff B. 1975. Hindsight = foresight: the effect of outcome knowledge on judgment under uncertainty. Journal of Experimental Psychology: Human Perception and Performance 1: 288-299.

Fox I, Srinivasan S, Vaaler P. 1997. A descriptive alternative to cluster analysis: understanding strategic group performance with simulated annealing. In Statistical Models for Strategic Management, Ghertman M, Obadia J, Arregle JL (eds). Kluwer: Amsterdam; 81-110.

Ghemawat P. 1991. Commitment: The Dynamic of Strategy. Free Press: New York. 
Gimeno J, Woo CY. 1996. Hypercompetition in a multimarket environment: the role of strategic similarity and multimarket contact in competitive deescalation. Organization Science 7: 322-341.

Grant RM. 1996. Prospering in dynamically-competitive environments: organizational capability as knowledge integration. Organization Science 7: 375-387.

Hamel G. 2000. Leading the Revolution. Harvard Business School Press: Boston, MA.

Hamel G, Prahalad CK. 1994. Competing for the Future. Harvard Business School Press: Boston, MA.

Hannan MT, Freeman JH. 1977. The population ecology of organizations. American Journal of Sociology 82: 929-964.

Hannan MT, Freeman JH. 1984. Structural inertia and organizational change. American Sociological Review 49: $149-164$

Hannan MT, Freeman JH. 1988. The ecology of organizational mortality: American labor unions. American Journal of Sociology 94: 25-52.

Hanssen-Bauer J, Snow CC. 1996. Responding to hypercompetition: the structure and processes of a regional learning network organization. Organization Science 7: 413-427.

Harvey M, Novicevic MM, Kiessling T. 2001. Hypercompetition and the future of global management in the twenty-first century. Thunderbird International Business Review 43: 599-616.

Henderson RM, Clark KB. 1990. Architectural innovation: the reconfiguration of existing product technologies and the failure of established firms. Administrative Science Quarterly 35: 9-30.

Hitt MA, Ireland RD, Camp SM, Sexton DL. 2001. Guest editor's introduction to the special issue strategic entrepreneurship: entrepreneurial strategies for wealth creation. Strategic Management Journal, Special Issue 22(6-7): 479-491.

Illinitch AY, D’Aveni RA, Lewin AY. 1996. New organizational forms and strategies for managing in hypercompetitive environments. Organization Science 7: $211-220$.

Jacobsen RL. 1988. The persistence of abnormal returns. Strategic Management Journal 9(5): 415-430.

Johnson RA, Greening DW. 1999. The effects of corporate governance and institutional ownership types on corporate social performance. Academy of Management Journal 42: 564-576.

Kirzner IM. 1973. Competition and Entrepreneurship. University of Chicago Press: Chicago, IL.

LaPierre CW. 1958. Technological change: what will it mean for management? In Management in a Rapidly Changing Economy, Fenn D (ed). McGraw-Hill: New York; 27-38.

Lau CM, Woodman RW. 1995. Understanding organizational change: a schematic perspective. Academy of Management Journal 38: 537-549.

Lei D, Hitt MA, Bettis R. 1996. Dynamic core competencies through meta-learning and strategic context. Journal of Management 22: 549-570.

Lin DY, Wei LJ. 1989. The robust inference of the Cox proportional hazards model. Journal of the American Statistical Association 84: 1074-1078.
MacMillan IC. 1989. How long can you sustain a competitive advantage? In The Strategy Planning Management Reader, Fahey L (ed). Prentice-Hall: Englewood Cliffs, NJ; 23-27.

March JG, Simon HA. 1958. Organizations. Wiley: New York.

Margulies N, Wallace J. 1973. Organization Change. Scott, Foresman: Glenview, IL.

McGahan AM, Porter ME. 1997. How much does industry matter really? Strategic Management Journal, Summer Special Issue 18: 15-30.

Mintzberg H. 1991. Learning 1, planning 0: reply to Igor Ansoff. Strategic Management Journal 12(6): 463-466.

Mintzberg H. 1994. That's not 'turbulence' chicken little, it's really opportunity. Planning Review November/December: 7-9.

Montgomery C. 1979. Diversification, market structure and firm performance: an extension of Rumelt's work. Doctoral dissertation, Purdue University, West Lafayette, IN.

Mueller DC. 1986. Profits in the Long Run. Cambridge University Press: Cambridge, UK.

Nault BR, Vandenbosch MB. 1996. Eating your own lunch: protection through preemption. Organization Science 7: 342-358.

Nohria N, Gulati R. 1996. Is slack good or bad for innovation? Academy of Management Journal 39: $1245-1264$

Porter ME. 1979. The structure within industries and companies' performance. Review of Economics and Statistics 61: 214-227.

Porter ME. 1980. Competitive Strategy. Free Press: New York.

Rindova VP, Kotha S. 2001. Continuous 'morphing': competing through dynamic capabilities, form, and function. Academy of Management Journal 44: $1263-1280$.

Roquebert JA, Phillips RL, Westfall PA. 1996. Markets vs. management: what 'drives' profitability? Strategic Management Journal 17(8): 653-664.

Rumelt RP. 1991. How much does industry matter? Strategic Management Journal 12(3): 167-185.

Rumelt RP, Schendel D, Teece DJ. 1991. Strategic management and economics. Strategic Management Journal, Winter Special Issue 12: 5-29.

SAS. 1989. SAS/STAT ${ }^{\circledast}$ User's Guide, Version 6 (4th edn), Vol. 2, SAS Institute: Cary, NC.

Schein EH. 1996. Culture: the missing concept in organization studies. Administrative Science Quarterly 41: $229-250$.

Schultz D. 1998. What's in a name? Industry Week 247: 20.

Schumpeter JA. 1950. Capitalism, Socialism and Democracy (3rd edn). Harper: New York.

Shane S, Venkataraman S. 2000. The promise of entrepreneurship as a field of research. Academy of Management Review 25: 217-226.

Sharma A. 2001. Consumer decision-making, salespeople's adaptive selling and retail performance. Journal of Business Research 54: 125-129. 
Sutcliffe K. 1994. What executives notice: accurate perceptions in top management teams. Academy of Management Journal 37(5): 1360-1378.

Teece DA, Pisano G, Shuen A. 1997. Dynamic capabilities and strategic management. Strategic Management Journal 18(7): 509-533.

Thomas LG. 1996. The two faces of competition: dynamic resourcefulness and the hypercompetitive shift. Organization Science 7: 221-242.

Tushman M, Anderson P. 1986. Technological discontinuities and organizational environments. Administrative Science Quarterly 31: 439-465.

Tushman M, Romanelli E. 1985. Organizational evolution: a metamorphosis model of convergence and reorientation. Research in Organizational Behavior 7: $171-222$.

Volberda HW. 1996. Toward the flexible form: how to remain vital in hypercompetitive environments. Organization Science 7: 359-374.

Wernerfelt B. 1984. A resource-based view of the firm. Strategic Management Journal 5(2): 171-180.

Wood G. 1978. The knew-it-all-along effect. Journal of Experimental Psychology: Human Perceptions and Performance 4: 345-353.

Zajac E, Bazerman M. 1991. Blind spots in industry and competitor analysis: implications of interfirm (mis)perceptions for strategic decisions. Academy of Management Review 16: 37-56. 